\title{
Aggressive superficial acral fibromyxoma of the great toe: A case report and mini-review of the literature
}

\author{
KAZUHIKO HASHIMOTO, SHUNJI NISHIMURA, NAOHIRO OKA, \\ HIROKI TANAKA, RYOSUKE KAKINOKI and MASAO AKAGI
}

Department of Orthopedic Surgery, Kindai University Hospital, Osaka-Sayama, Osaka 589-8511, Japan

Received May 25, 2018; Accepted July 3, 2018

DOI: $10.3892 / \mathrm{mco} .2018 .1669$

\begin{abstract}
Superficial acral fibromyxoma is a very rare soft tissue tumor. Fetsch et al first described the condition in 2001. It often occurs in the fingers and toes and has slow-progressive features. Since being described, a few cases occurring in the great toe have been reported. The present study indicated a case of a 37-year-old male kickboxer with a history of a rapid-growing lump under the nail of his left great toe with bone erosion. The patient was suspected to have a soft tissue tumor under the nail, such as a glomus tumor, as a differential diagnosis. However, a malignant soft tissue tumor as a differential diagnosis could not be ruled out because of the observed bone erosion. The patient underwent surgical excision, and pathologic analysis revealed superficial acral fibromyxoma. Twenty-four months after the treatment, he had no complaints or functional disorder and no recurrence was noted. Although an unusual diagnosis, surgeons should be aware of this tumor, which requires complete surgical excision and follow-up to detect recurrence. To the best of our knowledge, this is the first reported case of superficial acral fibromyxoma with bone erosion in a great toe.
\end{abstract}

\section{Introduction}

Benign soft tissue tumors with aggressive features are commonly encountered in clinical practice. When lesions are found on the toes or digits, one possible differential diagnosis is superficial acral fibromyxoma, a rare myxoid tumor with few cases described (1). Among them, superficial acral fibromyxoma is a relatively uncommon, slow-progressing, benign

Correspondence to: Dr Kazuhiko Hashimoto, Department of Orthopedic Surgery, Kindai University Hospital, 377-2 Ohno-Higashi, Osaka-Sayama, Osaka 589-8511, Japan

E-mail: hazzhiko@med.kindai.ac.jp

Abbreviations: MRI, magnetic resonance imaging; N/A, not applicable; VIM, vimentin; EMA, epithelial membrane antigen; SMA, $\alpha$-smooth muscle actin;

HMB45, human melanoma black-45

Key words: superficial acral fibromyxoma, great toe, bone erosion, toenail, benign tumor tumor. Superficial acral fibromyxoma sometimes leads to bone erosion, but a case with this characteristic in a great toe has not yet been reported. Herein, we describe a very rare clinical case in which such a lesion was found.

\section{Case report}

We describe the case of a 37-year-old male kickboxer, who presented with a lump under the nail of his left great toe. The lesion had been rapidly growing for the previous 6 months and measured about $2.4 \times 2.7 \mathrm{~cm}$ at presentation (Fig. $1 \mathrm{~A}$ and $\mathrm{B}$ ). The patient associated the onset of the lesion with kickboxing, but there had not been any trauma to the region. When he first noticed the mass, the patient did not experience any pain; however, he subsequently developed pain and as a result visited Kindai University Hospital (Osaka, Japan). Radiographic imaging showed an osteolytic lesion of the distal phalanx bone (Fig. 1C). Magnetic resonance imaging (MRI) revealed a $\mathrm{T} 1$ low, $\mathrm{T} 2$ high intensity lobular, cyst-like nodule under the nail (Fig. 1D and E). The MRI also showed a tumor infiltrating the distal phalanx bone. Surgical excision of the tumor with primary closure was performed, with the purpose performing a biopsy (Fig. 2A and B). The tumor was excised piece by piece with transverse skin incision. The nails, including the nail bed, were preserved. The tumor had partially invaded to the distal phalanx bone. The lesion had a firm consistency and was a light pink color (Fig. 2C). Histologically, spindle-shaped cells had proliferated in the myxocollagenous interstitium (Fig. 3A). No evidence of cellular atypia or mitotic figures was found. The immunohistochemical study revealed positivity for CD34 (sc-74499; dilution, 1:100) and negativity for S100 protein (sc-53438; dilution, 1:200), $\alpha$-smooth muscle actin (sc-53142; dilution, 1:200) (all from Santa Cruz Biotechnology, Dallas, TX, USA), epithelial membrane antigen (M0613; dilution, 1:400; Dako Corporation, Carpinteria, CA, USA), and desmin (60226-1-Ig; dilution, 1:50; Cosmo Bio, Tokyo, Japan) in the neoplastic cells (Fig. 3B-F). The diagnosis was superficial acral fibromyxoma. At 24 months of follow-up, the patient had no symptoms or signs of recurrence. Radiography of the bone after treatment showed no erosive lesion.

\section{Discussion}

Superficial acral fibromyxoma is a very rare soft tissue tumor that was first described in 2001 by Fetsch et al (1). It 

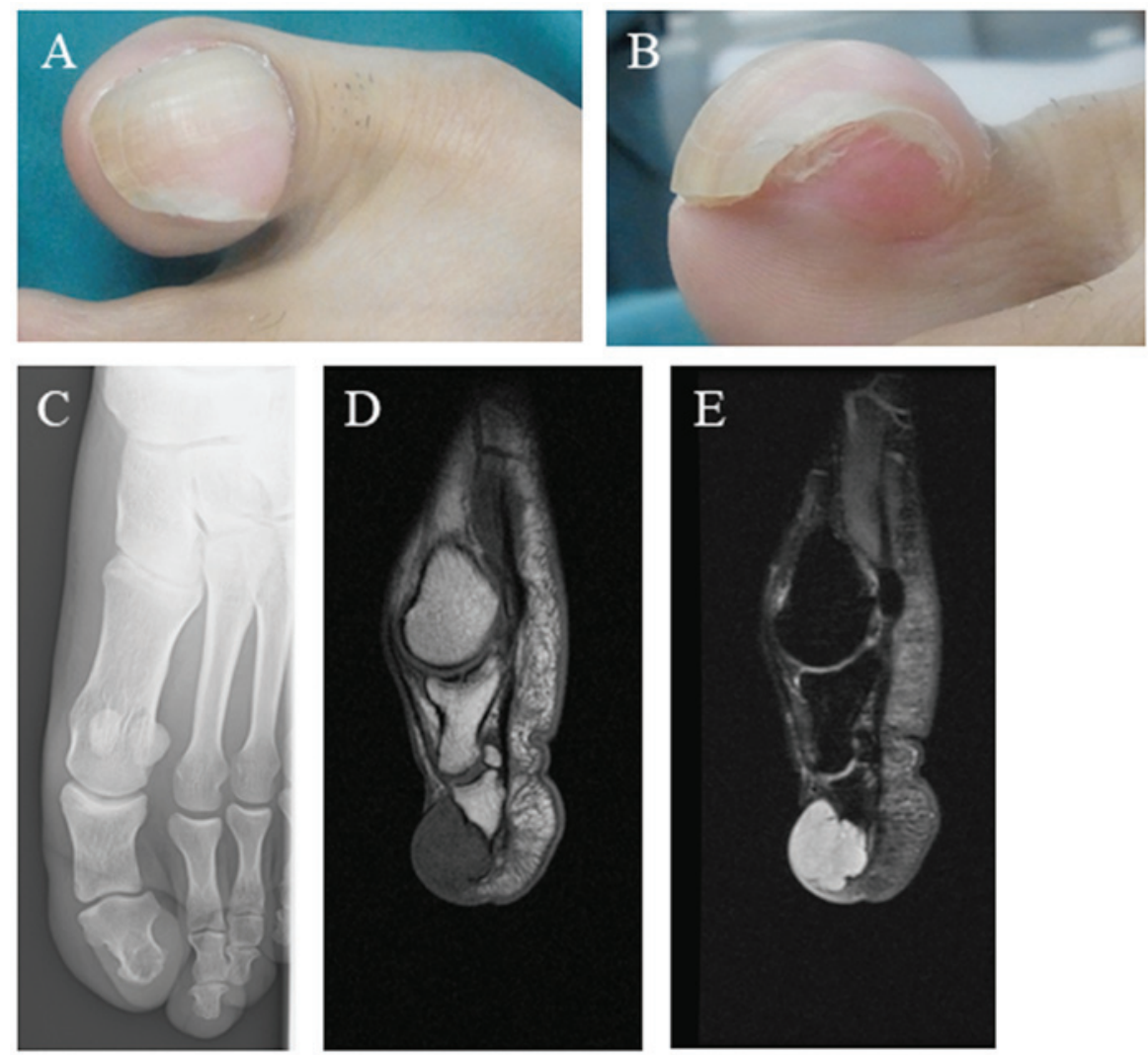

Figure 1. (A and B) Tumor appearance. (C) X-ray image of coronal view. Magnetic resonance sagittal images; (D) T1 weighted image, (E) T2 weighted image. (A and B) Budging of the nail was observed. (C-E) In the distal phalanx, bone erosion and invasion of the tumor mass were observed.
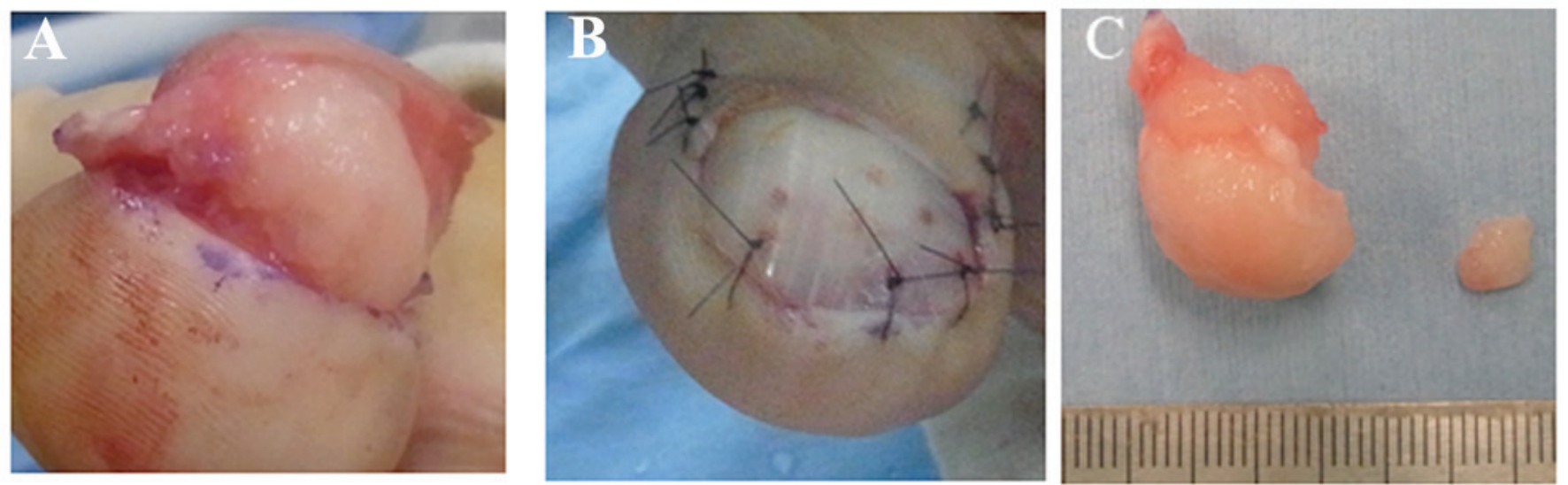

Figure 2. (A and B) Surgical findings. (C) Resected specimen, showing a light pink color.

is a slow-growing tumor (median duration of $\sim 3$ years) with a preponderance in men (male/female ratio of $2: 1$ ) and a mean age at presentation of 43 (range, 4-86) years $(1,2)$. The most frequently affected sites are the subungual and periungual regions of the toes or digits (2). Previously, superficial acral fibromyxoma of the great toe had been described in 8 cases (Table I) (3-8). Superficial acral fibromyxoma rarely occurs on the volar surface of the digits (1). In the current case, the tumor occurred on the volar side of the great toe under the nail. It presented as a single, relatively rapid-growing, and generally painless mass. Previous trauma of the affected site has only been reported in a very small number of cases $(1,9)$.
Previous superficial acral fibromyxoma of the great toe has also been reported to be slow-growing (3-8). Only two cases have been described in which the patients experienced pain, and only one case involved a patient with a traumatic history (Table I). In the current case, the patient showed a painful rapid-growing tumor without a traumatic history. Despite the absence of trauma, it was suggested that chronic stimulation may have promoted tumor growth and lead to the rapid growth rate. In $\sim 36 \%$ of superficial acral fibromyxoma cases, bone involvement may be present in the form of erosion (2), like in our case. Cases involving the great toe have shown no features of erosion or lytic bone lesions (Table I). We 

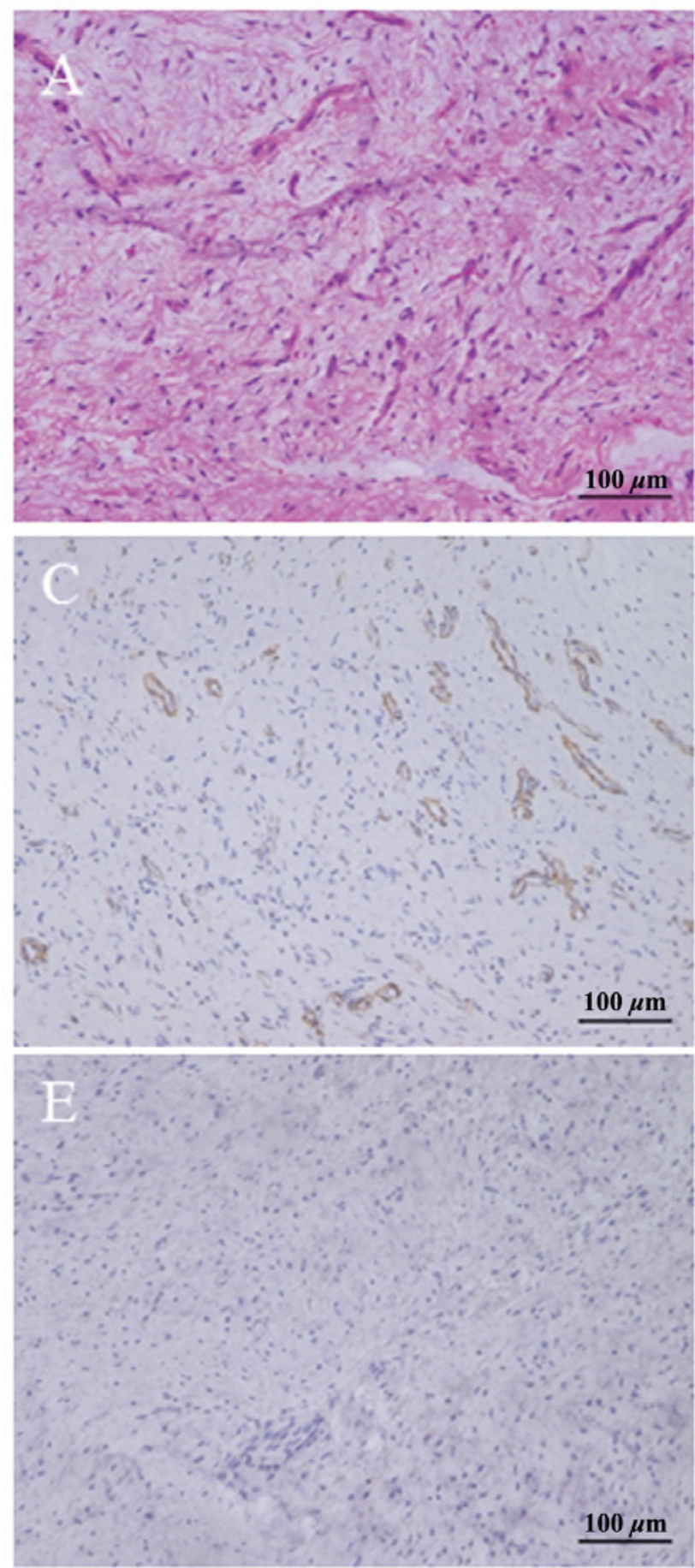
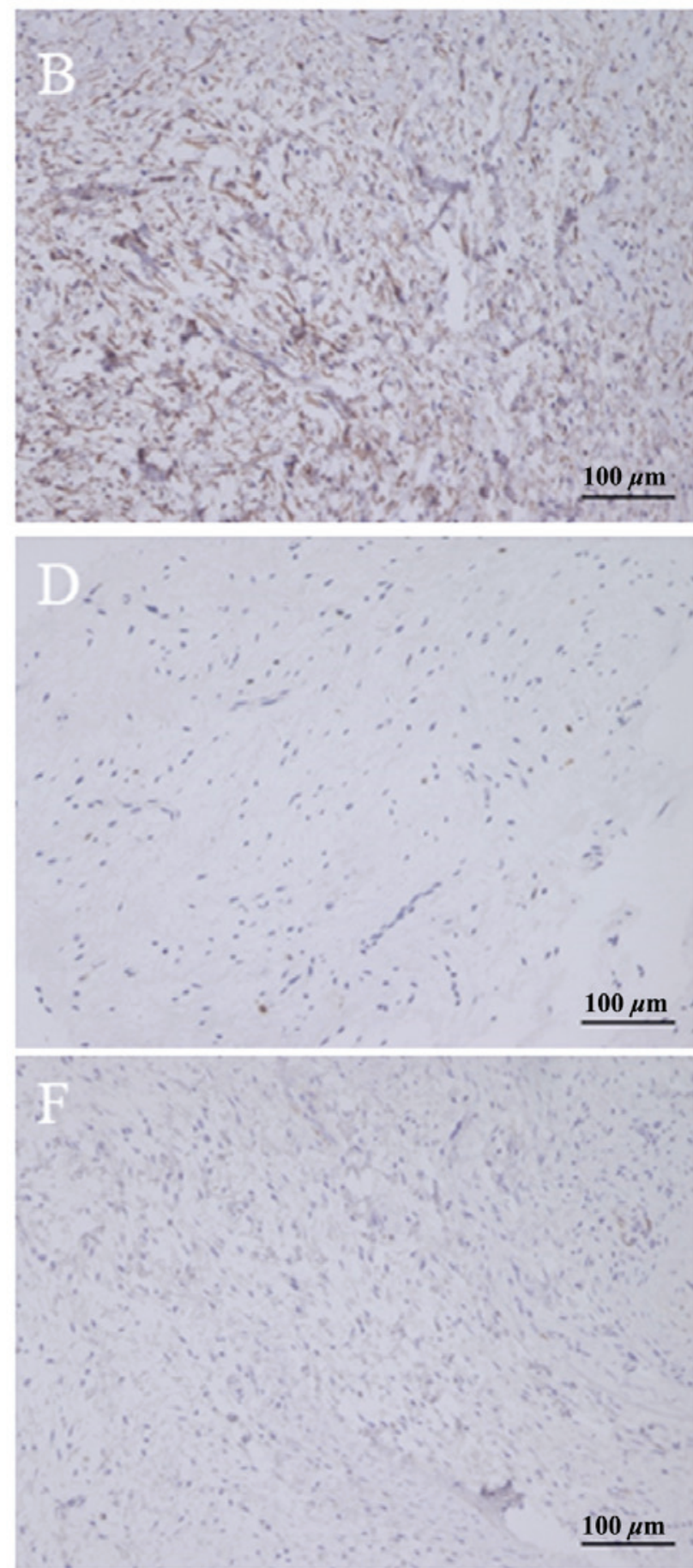

Figure 3. (A) Histological findings of hematoxylin and eosin staining showed that spindle-shaped cells had proliferated in the myxocollagenous interstitium. (B) Immunohistochemistry showed cells with positive staining for CD34, but no positively stained cells were observed for (C) $\alpha$-smooth muscle actin, (D) S-100, (E) epithelial membrane antigen or (F) desmin.

hypothesized that chronic stimulation may have promoted the invasion of the bone.

Simple resection is the basic treatment of superficial acral fibromyxoma $(1,2)$. Although the recurrence rate is $\sim 20 \%$, no malignant transformation has been documented $(1,2,9)$. All cases of superficial acral fibromyxoma of the toe that were treated with marginal resection showed no recurrence (Table I).

Macroscopically, superficial acral fibromyxoma is a non-capsulated, gelatinous or solid lesion with a size range of 0.6 to $5.0 \mathrm{~cm}$. It is located in the dermis and can extend to the subcutaneous tissue. On histologic examination, it consists of a proliferation of fibroblast-like cells with a myxocollagenous matrix. Mild nuclear atypia and mitotic figures are infrequently seen. Most reported cases are immunohistochemically positive for CD34 and CD99 and negative for epithelial membrane antigen, although the staining for these markers is variable. No reactivity is observed for $\mathrm{S} 100(1,2,10)$. Superficial acral fibromyxomas of the great toe show varied immunohistochemical features (Table I). We finally reached a 
Table I. Superficial acral fibromyxoma originating from a great toe.

\begin{tabular}{|c|c|c|c|c|c|c|}
\hline Authors, year & Demographic data & $\begin{array}{l}\text { Erosion or lytic } \\
\text { lesion of bone }\end{array}$ & Reactivity & Management & Recurrence & (Refs.) \\
\hline $\begin{array}{l}\text { Wakabayashi et al, } \\
2012\end{array}$ & $\begin{array}{c}51 \text { years, female } \\
14 \text { months history } \\
\text { No trauma } \\
\text { painless }\end{array}$ & - & $\begin{array}{l}\mathrm{CD}^{+} 0^{+}, \mathrm{CD}^{+} 4^{+}, \\
\mathrm{VIM}^{+}, \mathrm{CD}^{+}, \\
\mathrm{HMB}^{+} 5^{-}, \mathrm{EMA}^{-}, \\
\mathrm{S}^{-} 100^{-}, \alpha_{-} \mathrm{SMA}^{-}\end{array}$ & $\begin{array}{l}\text { 2-mm } \\
\text { wide margin }\end{array}$ & NR & (3) \\
\hline $\begin{array}{l}\text { Schwager et al, } \\
2015\end{array}$ & $\begin{array}{c}\mathrm{N}=3 \\
35 \text { years, male } \\
12 \text { months history } \\
\text { No trauma } \\
\text { Pain }^{+} \\
47 \text { years, male } \\
12 \text { months history } \\
\text { No trauma } \\
\text { Painless } \\
45 \text { years, female } \\
12 \text { months history } \\
\text { No trauma } \\
\text { Painless }\end{array}$ & - & $\begin{array}{c}\mathrm{CD}^{2} 4^{+}, \mathrm{S}-100^{-}, \\
\text {XIII }^{-}\end{array}$ & Marginal excision & NR & (4) \\
\hline Raghupathi et al, 2015 & $\begin{array}{c}27 \text { years, female } \\
2 \text { years history } \\
\text { No trauma } \\
\text { painless }\end{array}$ & - & N/A & Marginal excision & NR & (5) \\
\hline Moon et al, 2015 & $\begin{array}{c}46 \text { years, female } \\
2 \text { years history } \\
\text { No trauma } \\
\text { painless }\end{array}$ & - & $\begin{array}{c}\mathrm{CD} 68^{+}, \mathrm{CD}^{+} 9^{+}, \\
\mathrm{CD}^{-}, \mathrm{S}-100^{-}\end{array}$ & $\begin{array}{c}\text { Surgical excision } \\
\text { of the distal phalanx }\end{array}$ & NR & (6) \\
\hline Braga et al, 2017 & $\begin{array}{c}88 \text { years, male } \\
10 \text { years history } \\
\text { Trauma } \\
\text { Painless }\end{array}$ & - & $\begin{array}{c}\mathrm{CD}^{2} 4^{+}, \mathrm{CD}^{+} 9^{+}, \\
\mathrm{EMA}^{-}, \mathrm{S}-100^{+}\end{array}$ & Marginal excision & NR & (7) \\
\hline Robati et al, 2017 & $\begin{array}{c}18 \text { years, female } \\
2 \text { years history } \\
\text { No trauma } \\
\text { Painless }\end{array}$ & - & $\begin{array}{c}\mathrm{CD}^{+} 9^{+}, \mathrm{CD}^{-} 4^{-} \\
\mathrm{SMA}^{+}, \mathrm{VIM}^{+}\end{array}$ & Marginal excision & NR & (8) \\
\hline Current case & $\begin{array}{c}37 \text { years, male } \\
6 \text { months history } \\
\text { No trauma } \\
\text { Painless }\end{array}$ & + & $\begin{array}{c}\text { CD34+, S-100-, } \\
\text { EMA-, } \alpha-S M A-, \\
\text { desmin- }\end{array}$ & Marginal excision & NR & \\
\hline
\end{tabular}

NR, no recurrence; N/A, not available; VIM, vimentin; EMA, epithelial membrane antigen; $\alpha$-SMA, smooth muscle actin.

diagnosis with histological findings of hematoxylin and eosin staining and immunopositive findings of CD34.

The differential diagnosis of superficial acral fibromyxoma includes fibroma of the tendon sheath, myxoid neurofibroma, glomus tumor, giant cell tumor of the tendon sheath, sclerosing perineuroma, acral fibrokeratoma, cutaneous myxoma, myxoinflammatory acral fibroblastic sarcoma, fibrous histiocytoma, and dermatofibrosarcoma protuberans. In particular, superficial acral fibromyxoma should be considered in the differential diagnosis of glomus tumors when they develop under the nail. The histologic features seen on immunohistochemical analysis are used to distinguish superficial acral fibromyxoma from these other lesions $(1,2,10)$.

There are some limitations in the current study. First, we could not detect CD99 in the specimen by immunohistochemistry. However, we reached a diagnosis with other histological observations including hematoxylin and eosin staining and immunopositive findings. Second, we did not conduct a biopsy 
before resecting the tumor. We should have treated the tumor carefully because the radiological findings were doubtful for malignancy.

In conclusion, we described a rapid-growing superficial acral fibromyxoma of a great toe with bone erosion. If a soft tissue tumor occurs under the nail, we should suspect superficial acral fibromyxoma and we also should keep in mind that such tumors can grow aggressively.

\section{Acknowledgements}

Not applicable.

\section{Funding}

No funding was received.

\section{Availability of data and materials}

The datasets used and/or analyzed during the current study are available from the corresponding author on reasonable request.

\section{Authors' contributions}

$\mathrm{KH}, \mathrm{SN}, \mathrm{HT}$, NO and RK were involved in the acquisition of data. KH, SN and NO analyzed the data. MA made substantial contributions to conception and design and analysis and interpretation of data. $\mathrm{KH}$ and MA prepared the manuscript.

\section{Ethics approval and consent to participate}

The Ethics Committee of the Kindai University Faculty of Medicine approved the present study, and the patient provided informed consent to participate.

\section{Patient consent for publication}

The patient provided written informed consent.

\section{Competing interests}

The authors declare that they have no competing interests.

\section{References}

1. Fetsch JF, Laskin WB and Miettinen M: Superficial acral fibromyxoma: A clinicopathologic and immunohistochemical analysis of 37 cases of a distinctive soft tissue tumor with a predilection for the fingers and toes. Hum Pathol 32: 704-714, 2001.

2. Sawaya JL and Khachemoune A: Superficial acral fibromyxoma. Int J Dermatol 54: 499-508, 2015.

3. Wakabayashi Y, Nakai N, Takenaka H and Katoh N: Superficial acral fibromyxoma of the great toe: Case report and mini-review of the literature. Acta Dermatovenerol Croat 20: 263-266, 2012.

4. Schwager ZA, Mannava KA, Mannava S, Telang GH, RobinsonBostom L and Jellinek NJ: Superficial acral fibromyxoma and other slow-growing tumors in acral areas. Cutis 95: E15-E19, 2015.

5. Raghupathi DS, Krishnamurthy J and Kakoti LM: Cytological diagnosis of superficial acral fibromyxoma: A case report. J Cytol 32: 39-41, 2015.

6. Moon A, Yoon N and Kim HS: Myxoid dermatofibroma on a great toe: A case report. Int J Clin Exp Pathol 8: 7605-7609, 2015.

7. Braga JM, Bartosch I, Baldaia H, Oliveira I, Canelhas A and Silva Á: Superficial acral fibromyxoma: A rare soft tissue tumor. J Foot Ankle Surg 56: 653-655, 2017.

8. Robati RM, Dadkhahfar S and Rakhshan A: CD34 negative superficial acral fibromyxoma: A rare case report. Indian Dermatol Online J 8: 45-47, 2017.

9. Hollmann TJ, Bovée JV and Fletcher CD: Digital fibromyxoma (superficial acral fibromyxoma): A detailed characterization of 124 cases. Am J Surg Pathol 36: 789-798, 2012.

10. Kazakov DV, Mentzel T, Burg G and Kempf W: Superficial acral fibromyxoma: Report of two cases. Dermatology 205: 285-288, 2002 . 